\title{
Short Sea Shipping and Its Role in Logistics Supply Chains: A European Perspective
}

\author{
Peter B. Marlow* and Ana C. Paixao Casaca*
}

\begin{abstract}
This paper has presented a brief description of the SSS industry in Europe and has discussed what is meant by this industry, what types of ships are involved, what cargoes are carried, what are the main geographical areas of operations, what are the industry's strengths and weaknesses, and what users require from the industry before it can become a realistic choice for many in multimodal logistics transport chains.
\end{abstract}

Keywords: Europe, Logistics, Short Sea Shipping, Supply Chains.

\section{INTRODUCTION}

In Europe the shift of freight from road to sea and especially to short sea shipping (SSS) is considered one of the major objectives of the common transport policy (CTP) as witnessed by the many documents and press releases from the various European Union (EU) authorities (Commission of the European Communities,1992,1995,1998,1999; Council of the European Union, 2000). Despite these desires, such a shift is far from being a reality since road transport is still regarded as the mode which most closely meets customer requirements in terms of transit times, flexibility, reliability, frequency and accessibility. Statistics from EUROSTAT (2000) indicate that road transport has the largest market share by mode. Given that EU freight transport is expected to grow by about $2 \%$ annually until 2017 (Commission of the European Communities, 1992 1997), a careful examination must be made to assess whether SSS could become a viable alternative to road and could become integrated into multimodal transport chains.

\section{WHAT IS MEANT BY SHORT SEA SHIPPING?}

Given the complex nature of the market and appreciating that vessels which make up this shipping sector are not homogeneous, defining SSS is not an easy task and often the definition varies from one study to another (Peeters et al., 1995). This complexity was explained by Marlow and others (1997) when they stated that SSS

\footnotetext{
- Logistics and Operations Management. Cardiff Business School. Colum Drive Cardiff CF10 3EU

E-mail: marlow@cardiff.ac.uk
} 
can embrace different ships, from conventional to innovative ones (such as fast ships) involving a variety of cargo handling techniques, ports, networks and information systems, which when studied from engineering, economics, logistics, marketing or regulatory view points increase this complexity even further (Marlow, Pettit and Scorza, 1997). Four different ship types have been identified (Hoogerbeets and Melissen, 1993).

The traditional single-deck bulk carriers employed on a voyage basis are mainly engaged in the carriage of the neo-bulk cargoes, which embrace forest and steel/metal products, unless the vessel's construction is flexible enough to carry the traditional dry bulk cargoes. The next category is a fleet of container feeder vessels, that have been replacing the traditional general cargo vessels engaged in the movement of break-bulk cargoes, which carry high value cargoes and provide a link for deep-sea container vessels employed in the transoceanic East-West and North-South bound voyages. These ships having a capacity of between 150 and 500 twenty-foot equivalent units (TEUs) operate under the schedule of the deep-sea vessels and are engaged in four broad regional areas, namely the Mediterranean Sea, the English Channel and Atlantic Coast, the Baltic Sea and other small feeder routes.

The ferries engaged in SSS constitute the third category and are seen as an extension of road transport and even rail if they are prepared to take on board rail wagons, although this last option requires the commitment of high capital and can only be employed on routes whose terminals are prepared to receive such technology. These ships are capable of carrying both passengers and/or a whole range of cargoes that embraces palletised cargo, accompanied and unaccompanied trailers, semitrailers, pallets, swap-bodies, railway wagons, cassettes, project cargo and machinery. SSS operations in the Baltic Sea are a clear example of this. Finally, there is a fleet of bulk carriers and tankers, whose dimensions are less than 3000 deadweight (DWT) tonnes engaged in the pure and conventional dry and liquid bulk trades such as mineral oil products, chemicals, liquefied petroleum gas (LPG), coal, iron ore and grain. While this four part classification agrees with the one made by Hoogerbeets and Melissen (1993) a fifth one could also be added, made up of sea-river ships often with retractable wheelhouses to allow their passage under bridges.

Ship type is only one of the many different selective criteria which may be used to identify SSS. The following are also important though the list should not be considered exhaustive (Marlow, Pettit and Scorza, 1997)..

1. Geographically, SSS can be defined, for example, in terms of trade flows between specific areas, seas crossed by the relevant links or corridors between two supernational regions. As far as Europe is concerned, there is a clear distinction between short sea trades in the north, which concern only European countries, and short sea trades in the south or Mediterranean area which include North African and Near Eastern, as well as European countries.

2. Politically, SSS can be defined in terms of trade flows affecting certain blocks of countries belonging to supernational groupings. In this case, as far as Europe is concerned the problem is, do we consider just EU members, EU members 
and countries associated with the EU through bilateral agreements, countries within the European Economic Area (EEA) or any other countries or groupings? On 1 May 2004 the EU was expanded further by the accession of ten east European countries.

3. Technically, SSS can be defined in terms of trade flows carried on ships with certain technical characteristics. These can usually be Ro-Ro vessels, conventional ferries, fast ferries (of which there exist an ever growing variety), bulkers and tankers or, considering a different perspective, liners and tramps. Another distinguishing criterion of relevance could be based on the cargo loading systems. In this case which types of ship are to be included and on the basis of which criteria? For example SSS could include one or all of Lo-Lo cargo units (with vertical cargo lifting), Ro-Ro cargo units (with horizontal discharging), suction discharge or self-unloading vessels. Ships used to carry live animals (e.g. sheep) are often referred to as Wo-Wo vessels since the animals walk on and off the ships.

4. In terms of dimension, SSS can be defined in terms of trade flows on ships up to a certain size, measured alternatively in gross tonnes (gt) or in deadweight tonnes (dwt) or in both. Up to which tonnage are the ships to be included and which is the best unit of measure, gt or dwt? The choice of dwt could penalise, in the sense of under-estimating their roles, car-passenger (car-pax) vessels.

5. Functionally, SSS can be defined in terms of trade flows relating to direct links between two ports within a specific country, whether or not these services, which although deployed between two ports within that country, are only part of a wider intercontinental-transoceanic route. Thus should feedering services be included which are crucial to the trunk services pivoting on transhipment load/unload centres and performed between two ports within the fixed territory although not a part of broader international services?

6. In respect of the nature of cargo, SSS can be defined in terms of trade flows concerning alternatively the carriage of freight or passengers or both.

7. In terms of regulations, SSS can be defined in terms of trade flows concerning either domestic links and/or international links. In some cases this distinction also has a political dimension as the freedom of performing domestic services in foreign countries conflicts with the trade reservation to national flagged ships ('cabotage' or 'coastal' services).

8. Territorially, SSS can be defined in terms of trade flows relating to navigation on all waterways; open sea, lakes, canals, inland waterways, gulfs, etc. This is also the consequence of the growing implementation of multimodalism, so that in some cases it is difficult to distinguish interconnecting flows. However, should all these types of waterborne transport be considered in the context of SSS? 
Clearly an undisputed and general definition is difficult to determine but the usual approach supports the characterisation of short sea markets in terms of ship sizes and the shipping markets in which they are engaged (Peeters, 1993). While Ro-Ro services compete on near sea and short distances with road transport for reasons of cost and physical geography, Lo-Lo services compete over longer distances with rail transport. The use of SSS implies a broken logistics/transport chain which requires the cargo transfer between modes. Such transfers are provided in facilities (interfaces) such as ports/dedicated terminals and dry ports which also require effective inland transport infrastructure comprising surface transport modes, including inland waterways (Caspers and ter Brugge, 1993). To prevent unduly long dwell times it is necessary to coordinate logistics operations as these interfaces. The question remains: can SSS ever be a realistic alternative to road transport?

\section{THE STRENGTHS AND WEAKNESSES OF SHORT SEA SHIPPING ${ }^{2}$}

\section{The strengths}

The EU, with a coastline in excess of 67,000 kilometres has between $60 \%$ and $70 \%$ of its industrial and production centres located within $150-200 \mathrm{~km}$ of the coast, and a network of inland waterways of $25,000 \mathrm{~km}$ of which $12,000 \mathrm{~km}$ are part of the combined transport road network (Commission of the European Communities, 1992, 1995). Such conditions provide SSS with a geographical advantage over other modes of transport thereby facilitating the door-to-door transport of certain cargoes (namely wet and dry bulk) by coastal and sea-river vessels. This geographical advantage can have tremendous economic impacts as SSS can contribute to the integration, cohesion and economic development of the peripheral areas (and even beyond) of the EU. These economic impacts can also be extended to SSS companies.

By offering services at lower freight rates due to inherent economies of scale and distance, these companies can employ and exploit an underused available capacity without immediately incurring high investment in additional vessels. Shipping in general, and SSS in particular, are capital-intensive industries, which could perhaps be considered a weakness due to the volatile nature of the market and sometimes the difficulty of getting finance from financial institutions for new entrants into this business, but the reality is that this can be seen as a strength since it gives the shipping players already in the market a tremendous competitive advantage. SSS players already possess the most expensive assets involved in intermodal freight transport and so have a good position from which to develop transport systems.

To this should be added the virtually unlimited capacity of the sea. This does not require costs to be incurred in the building of sea-lanes, although exception is made

\footnotetext{
2 Based on Paixao and Marlow,2002.
} 
for any additional superstructure along the coast that may contribute to the safety of navigation and which may help the commercial exploitation of these broken transport chains, such as in the case of the vessel traffic management information systems (VTMIS). Deriving from this unlimited capacity is the advantage that SSS has in being able to use the oceans 7 days per week, 52 weeks per year, when certain countries are imposing timetable restrictions on driving hours during the night and at weekends (France, Portugal, Spain), while others are introducing tax schemes such as the Eurovignete, a traffic tax payable as a function of distance travelled and the number of days of staying in a particular country.

Consequently, and unless new ship technologies have to be introduced, port investments and port maintenance costs are low when compared with the ones required by road and rail infrastructure whose external costs are increasing considerably. The development of road and rail mode networks requires huge investments not only to build both the road surfaces and the railway lines by also additional tunnels and bridges, whereas ports are the only land area or physical space required by SSS. Since SSS does not require a huge land take to function we can conclude that, in this regard, SSS is environmentally friendly although improvements will need to be made at ships' engine level and at the entry and exit of goods through ports to avoid bottlenecks and therefore friction costs.

Using SSS as an alternative means of freight movement reduces not only the number of trucks that daily congest about $4000 \mathrm{~km}$ of road networks located at the heart of Europe and focal points such as the Netherlands and Belgium but also associated social costs, which cannot be removed/reduced unless huge investments in infrastructure are made at the expense of yet more social cost. In terms of air pollution SSS produces less carbon dioxide $\left(\mathrm{CO}_{2}\right)$ than other modes of transport, which can help the Community to reach $\mathrm{CO}_{2}$, carbon monoxide (CO) and hydrocarbon (HC) targets as established in the Kyoto Environmental Protocol. Improvements, however, need to be made to the nitrogen oxide $\left(\mathrm{NO}_{\mathrm{x}}\right)$ and sulphur dioxide $\left(\mathrm{SO}_{2}\right)$ emission levels though these are still lower per tonne kilometre than those from the other modes of transport.

In terms of safety SSS and IWW are both known to have a relatively good safety record when compared to the other modes of transport so a transfer of traffic from road to SSS should bring about a reduction in the number of accidents and their associated costs. An additional advantage would be higher safety levels in the transport of dangerous goods.

The UK government has recognised these environmental and social benefits and operates a scheme called the Freight Facilities Grants Scheme under which grants are paid, towards the capital cost of rail and inland waterway freight equipment and facilities, in cases where the traffic would otherwise move by road. Clearly this cost reduction could help compensate for the increase in generalised costs caused by using a slower mode of transport.

The advantages of SSS can be said to fall into seven main groups: geographical advantages, financial advantages, knowledge/skills-based/human resources advantages, energy advantages, environmental advantages, underused capacity for expansion, and positive effects in ancillary activities. While all these reasons come 
out in support of the development of SSS the fact is that often the choice of mode is based more on economic factors such as costs, time, flexibility, quality, and reliability and these are the reasons for making use of road transport.

\section{The weaknesses}

Despite the advantages summarised above SSS is faced with various disadvantages, the importance of which may outweigh the strengths. By its very nature SSS cannot offer a door-to-door transport service, the exception being for liquid and dry bulk cargoes, which often are delivered to dedicated and private terminals. This disadvantage arises from SSS being part of a broken chain. Therefore, to complete a door-to-door service, SSS requires the collaboration of rail and/or road modes for the pre- and end-carriage (collection and delivery) legs, not to mention the use of dedicated terminals and a network of well-located inland terminals. The approach made by the European Commission in developing a policy on infrastructure levels which has resulted in the trans-European networks (TENs), although an important step towards the integration of SSS in multimodal/intermodal transport systems, is not enough. The implementation of an organisational culture by shipping companies will be an important step towards the development of a corporate structure which reflects the new strategies and best practices that will contribute to improving SSS operations and to focus more on customer service.

Ports and/or terminal operators must carefully plan the development of a port/dedicated terminal layout so that its operations can be carried out in the smoothest way possible and therefore eliminate all sorts of wastes and associated friction costs found in a port environment, which extend to the whole network. This helps to reduce the overall transit time of cargoes which, in certain trade routes, is considerably longer than that of unimodal transport, namely road-haulage. To this should be added the additional inventory costs, which results in opportunity costs for shippers and which increase total logistics costs and is the reason why shippers decide to choose unimodal transport rather than multimodal/intermodal forms. Despite this drawback, studies have shown that shippers would be prepared to revise their decisions if SSS rates (including land rates) were 35\% less than the cost of transport performed by road alone, to offset the additional inventory costs in the logistics pipeline (European Commission, 1996). Although this may be seen as an opportunity for increasing market share, it is an unfair situation since, of all the transport modes, maritime transport is the one that has already internalised its external costs. The lack of a level playing field in the internalisation of transport external costs by other modes creates an artificial demand for (mainly) road transport. If other modes proceeded accordingly this difference of $35 \%$ would be reduced considerably, and all modes of transport would, hence, be competing on an equal footing.

Contributing to the opportunity costs is the lack of integration between seaborne and surface modes of transport either in terms of interconnectivity, interoperability or compatibility of information technology/information systems (IT/IS), which increases the lack of flexibility compared to road-haulage. Road-haulage vehicle capacity provides for frequent departures/deliveries on a regular basis as required by time- 
based logistics strategies and that makes road the performance benchmark of the transport industry. Therefore, the implementation of the lean port concept would contribute to reducing this gap since it is developed on JIT, flexibility of operations, TQM and teamwork issues.

This lack of flexibility in terms of service departures/arrivals, also results in SSS incurring additional costs accruing from the use of expensive infrastructures, namely seaports and dry ports, and cargo handling costs as a result of indirect cargo transfer operations, the performance of which is critical for the success or failure of this mode's integration with multimodal/intermodal transport systems. These handling costs embrace expenses incurred at both physical and informational levels. Two crucial expenses have been identified as a result of a number of wastes within the present working processes. The first one is the costs incurred in double handling and in the storage of goods, due to the inefficiency of the flows, until cargo is despatched to its final destination. Storage is known for not creating value and so any capital tied up in it prevents the shipper and/or receiver from making use of it in other investments that could render profit to the organisation and from meeting their customers' requirements faster.

The second is the amount of paperwork required. A recent study has demonstrated that the documentary procedures required for road transport are far less than the ones required for SSS. The considerable number of documents processed every time a ship goes into port, which can be seen in the publication Guide to Port Entry, gives a fairly good idea of the amount of bureaucracy that SSS has to overcome, despite the introduction of the cargo form T2L which can contribute to streamlining the movement of cargo within the Single European Market (Commission of the European Communities, 1992, 1999; European Commission, 2000).

The lack of good rail links often stops the development of strategic partnerships with other transport operators, namely rail, and the planning of direct discharge operations that contribute to the development of efficient intermodal/combined services. The lack of implementation of compatible systems and the inefficient use of IT contribute to the low speed of port operations and the overall inefficiency of ships' operation. Moreover, the complex hierarchical structure of ports in general contributes to the lack of empowerment of their labour to make decisions that immediately could reduce, or eliminate in the best case, any sort of bottlenecks. Unless such decisions are made, the performance of SSS in respect of transit times, punctuality, flexibility, availability and frequency of services, the timing of departures and arrivals, reliability, and control will be very poor.

It would appear that the weaknesses inherent in SSS outnumber and outweigh any advantages which it possesses. The major competitors to SSS are road and rail (both of which have their own strengths and weaknesses) and it does not appear fanciful to suggest that the logistics market would be best served by combining the modes in such a way that their respective strengths are combined and their disadvantages minimised. 


\section{THE COMPETITIVENESS OF SSS IN MULTI-MODAL LOGISTICS SUPPLY CHAINS}

A logistics service may take many forms and be comprised of many aspects depending on the customers' requirements. A high level of customer service is the key to survival and prosperity in the market. Recently, Paixao Casaca (2003) undertook a study of the SSS industry in Europe. She surveyed various parties including logistics operators, shippers' associations, and intermodal rail operators in the broad geographical area of the extended European Union. Her survey was in two parts. The first survey had as its objective the identification, from the shippers' point of view, of the attributes needed by SSS when integrated into multimodal transport chains; while the objective of the second survey was to identify logistics strategies that SSS should use when developing their corporate strategies. Her results indicate the following:

More than $50 \%$ of the market share is comprised of third parties that operate their own short sea shipping services. The present market structure allows any freight forwarder to vertically integrate its operations through chartering ships, on either a time or voyage basis, without incurring large investments on the wet side of the operations. It follows that the costly land infrastructure must be properly organised too. Due to the low capital barrier to entry there is an increasing number of small short sea operators in this market which accounts for the overcapacity that contributes to the low freight rates and consequently to the strong bargaining power of the end users. It would appear to be a buyer's market.

She found that $52.4 \%$ of companies employed between 10 and 50 people, and that her respondents had, on average, 20.5 years experience of working in the industry but that most of the companies had been established within the last 30 years. Older companies tend to be characterised by hierarchical organisational structures that sometimes cannot respond to contemporary logistics trends regarding customer service. However $85 \%$ of respondents were able to make decisions on the choice of mode(s) within a multimodal service which suggests that this industry, at least in Europe, is adopting flatter organisational structures.

Clearly SSS will never be suitable for all cargoes all of the time and very few SSS companies will handle a large variety of cargoes because of the logistics requirements of different commodities. Table 1 shows that the most commonly carried cargoes were machinery, and manufactured products. 
Table 1. Cargoes Carried

\begin{tabular}{lr|lr}
\hline Cargo & Per cent & Cargo & Per cent \\
\hline & & continued & \\
Machinery & 18.1 & Chemicals & 4.2 \\
Manufactured goods & 16.7 & Solid mineral fuels & 4.2 \\
Foodstuffs & 9.7 & Metal waste & 4.2 \\
Transport equipment & 8.3 & Fertilisers & 2.8 \\
Building materials & 6.9 & Ores & 1.4 \\
Agricultural produce & 5.6 & Others & 18.1 \\
Sub-total & 65.3 & Sub-total & 34.9 \\
continued & & Total & 100.0 \\
\hline
\end{tabular}

Note: Rounding errors

Source: Derived from Paixao Casaca, 2003.

In SSS the three most common ways of carrying cargo are in containerised, palletised or dry bulk forms followed by semi-trailers and trailers. Over one third $(35.3 \%)$ of respondents focus on only one form of cargo while $17.6 \%$ handle two forms i.e. $53 \%$ of the operators carry only 1 or 2 forms of cargo. This result follows from the types of commodity carried and the nature of the ships that are used. Containerships are predominant in SSS operations with a $37 \%$ market share, almost twice as big as the next ship type (multipurpose carriers) which has a $20 \%$ share. In terms of trading areas within Europe, the NE-SE Atlantic and NE-SE Mediterranean trades together account for $51.4 \%$ of the SSS markets.

Given this profile of ship types, forms of cargo, and geographical areas of operation it is clearly possible for SSS to be a chosen mode of transport. The reasons why it is not the preferred mode or the one chosen most often lie in how decision makers perceive it. Compared to its competitors it is viewed as reactive, maintaining prices, slow, conservative, a lagger in technological innovation, and 'invisible'. This last point stems from a general lack of knowledge or awareness of this industry which has contributed to SSS being isolated and not involved in collaborative strategies with other modes of transport. To overcome this inertia SSS needs to become more proactive and to provide services which are required and valued by the users. Paixao Casaca's (2003) survey identified and ranked the six most important characteristics required by the users as:

Carrier's technical capabilities

Service quality

Pricing policy

Ability to innovate

IT/IS capabilities

Marketing activities

For SSS to become an effective choice or even a preference it should, as a 
minimum market-qualifier, offer good performance in each of these areas. This may still not make it an order-winner but at least it would be in the game.

\section{CONCLUSION}

This paper has presented a brief description of the SSS industry in Europe and has discussed what is meant by this industry, what types of ships are involved, what cargoes are carried, what are the main geographical areas of operations, what are the industry's strengths and weaknesses, and what users require from the industry before it can become a realistic choice for many in multimodal logistics transport chains.

These findings should encourage the European Union in its development of new intra-European transport concepts based on multimodal approaches capable of supporting the movement of goods, reaping the economic benefits offered by each transport mode individually and, providing the lowest cost option when acknowledging social impacts, drive these services providers into adopting a completely new strategy approach so that they can compete on quality, service, and lead-time rather than on cost alone since quality in transport has become paramount (Paixao Casaca, 2003).

SSS should not be viewed in isolation but rather as part of a network of transport. It is the efficiency of the network that matters in terms of meeting the customer's logistics requirements and trade-offs (e.g. inventory, warehousing, speed of transit) must be effected. The interfaces between the modes must allow for efficient cargo transfer and be connected to good transport infrastructure to allow upstream and downstream movement. Equally important is the flow of information which accompanies the cargoes, and information systems must be developed which link all the players in the chain and provide them with accurate real time information. Any discussion of SSS must be placed within the context of ports and transport infrastructure. SSS is not a peripheral mode of transport and should be more closely integrated with other modes of transport in deeds as well as thoughts.

\section{REFERENCES}

Caspers F.N. and ter Brugge R.T. (1993). "Logistics requirements and short sea shipping". Proceedings from the First European Research Round Table Conference on Short Sea Shipping, 26-27 November 1992. London: Technical University Delft, Lloyds of London Press, pp40-51.

Commission of the European Communities (1992). Communication from the

Commission. The future development of the common transport policy. A global approach to the construction of a community framework for sustainable mobility, COM (92) 0494 Final, Office for Official Publications of the European Communities, Luxembourg. 
Commission of the European Communities (1995). Communication from the

Commission to the Council to the European Parliament the Economic and Social Committee and the Committee of the Regions. Development of Short Sea Shipping in Europe. Prospects and Challenges, COM 9950317 Final, Office for Official Publications of the European Communities, Luxembourg.

Commission of the European Communities (1997). Communication from the Commission to the European Parliament and the Council. Intermodality and Intermodal freight transport in the European Union. A systems approach to freight transport. Strategies to enhance efficiency services and sustainability, COM (97) 243 Final, Office for Official Publications of the European Communities, Luxembourg.

Commission of the European Communities (1998). Communication from the

Commission to the Council of the European Parliament, the Economic and Social Committee and the Committee of the Regions. The common transport policy: sustainable mobility. Perspectives for the future, COM (98) 0716 Final, Office for Official Publications of the European Communities, Luxembourg.

Commission of the European Communities (1997). Communication from the

Commission to the Council to the European Parliament, the Economic and Social Committee and the Committee of the Regions. The development of SSS in Europe. A dynamic alternative in sustainable transport chain. A second two yearly alternative in sustainable transport chain. A second two yearly progress report, COM (99) 0317 Final, Office for Official Publications of the European Communities, Luxembourg.

Council of the European Union (2000). http://ue.eu.int/newsroom/main.cfm? LANG=1, dated 4 October 2000.

European Commission (1996). Transport research APAS, short sea shipping. Office for Official Publications of the European Communities, Luxembourg, 1996.

European Commission (1998). CODISSART - comparison of documentation in short sea shipping and road transport, dated17 April 2000.

EUROSTAT (2000). EU transport in figures. Statistical pocket book. Office for Official Publications of the European Communities, Luxembourg, July 2000, http://europea.eu.int/comm/transport/tif/tif july2000.pdf, dated 4 October 2000

Hoogerbeets, J, and Melissen P. (1993). "Facilitation of short sea shipping: improvements in the sea land interface: The Dutch case". Proceedings from the First European Research Round Table Conference on Short Sea Shipping, 26-27 November 1992. London: Technical University Delft, Lloyds of London Press pp 346-50.

Marlow PB, Pettit SJ, and Scorza AD (1997). Short sea shipping in Europe. Analysis of the UK, Italian Markets, Occasional Papers No. 42, Department of Maritime Studies and International Transport, Cardiff,.

Paixao A.C. and Marlow P.B. (2002). "Strengths and weaknesses of short sea shipping". Marine Policy 26,, pp167-178 
Paixao Casaca A.C.,(2003). The competitiveness of short sea shipping in multimodal logistics supply chains. Unpublished PhD thesis, Cardiff University, June 2003.

Peeters C. (1992). "Keynote address: European Short Sea Shipping”. Proceedings from the First European Research Round Table Conference on Short Sea Shipping, 26-27 November 1992. London: Technical University Delft, Lloyds of London Press, pp xxx-xxxii.

Peeters C. Verbeke A, Declercq E, and Wijnolst N (1995). Chapter I. Identification and analysis of existing intra-European traffic for each relevant category of goods and transport corridor. Analysis of the competitive position of short sea shipping. Development of policy measures. The corridor study. Delft: Delft University Press. pp 1-62. 